\title{
Cost-effectiveness and budget impact analyses of a colorectal cancer screening programme in a high adenoma prevalence scenario using MISCAN-Colon microsimulation model
}

\author{
Arantzazu Arrospide ${ }^{1,2,3^{*}}$ (D), Isabel Idigoras ${ }^{4}$, Javier Mar ${ }^{1,2,3,5}$, Harry de Koning ${ }^{6}$, Miriam van der Meulen ${ }^{6}$, \\ Myriam Soto-Gordoa ${ }^{1,2,3}$, Jose Miguel Martinez-Llorente ${ }^{7}$, Isabel Portillo ${ }^{4}$, Eunate Arana-Arri ${ }^{8}$, Oliver Ibarrondo ${ }^{1}$ \\ and Iris Lansdorp-Vogelaar ${ }^{6}$
}

\begin{abstract}
Background: The Basque Colorectal Cancer Screening Programme began in 2009 and the implementation has been complete since 2013. Faecal immunological testing was used for screening in individuals between 50 and 69 years old. Colorectal Cancer in Basque country is characterized by unusual epidemiological features given that Colorectal Cancer incidence is similar to other European countries while adenoma prevalence is higher. The object of our study was to economically evaluate the programme via cost-effectiveness and budget impact analyses with microsimulation models.

Methods: We applied the Microsimulation Screening Analysis (MISCAN)-Colon model to predict trends in Colorectal Cancer incidence and mortality and to quantify the short- and long-term effects and costs of the Basque Colorectal Cancer Screening Programme. The model was calibrated to the Basque demographics in 2008 and age-specific Colorectal Cancer incidence data in the Basque Cancer Registry from 2005 to 2008 before the screening begun. The model was also calibrated to the high adenoma prevalence observed for the Basque population in a previously published study. The multi-cohort approach used in the model included all the cohorts in the programme during 30 years of implementation, with lifetime follow-up. Unit costs were obtained from the Basque Health Service and both cost-effectiveness analysis and budget impact analysis were carried out.
\end{abstract}

Results: The goodness-of-fit of the model adaptation to observed programme data was evidence of validation. In the cost-effectiveness analysis, the savings from treatment were larger than the added costs due to screening. Thus, the Basque programme was dominant compared to no screening, as life expectancy increased by 29.3 days per person. The savings in the budget analysis appeared 10 years after the complete implementation of the programme. The average annual budget was $€ 73.4$ million from year 2023 onwards.

(Continued on next page)

\footnotetext{
* Correspondence: arantzazu.arrospideelgarresta@osakidetza.eus

1 Gipuzkoa Primary Care - Integrated Health Care Organizations Research

Unit, Alto Deba Integrated Health Care Organisation, Avda Navarra 16, 20500

Arrasate-Mondragón, Gipuzkoa, Spain

${ }^{2}$ Health Services Research on Chronic Patients Network (REDISSEC), Arrasate -

Mondragón, Gipuzkoa, Spain

Full list of author information is available at the end of the article
}

(c) The Author(s). 2018 Open Access This article is distributed under the terms of the Creative Commons Attribution 4.0 International License (http://creativecommons.org/licenses/by/4.0/), which permits unrestricted use, distribution, and

reproduction in any medium, provided you give appropriate credit to the original author(s) and the source, provide a link to the Creative Commons license, and indicate if changes were made. The Creative Commons Public Domain Dedication waiver (http://creativecommons.org/publicdomain/zero/1.0/) applies to the data made available in this article, unless otherwise stated. 
(Continued from previous page)

Conclusions: This economic evaluation showed a screening intervention with a major health gain that also produced net savings when a long follow-up was used to capture the late economic benefit. The number of colonoscopies required was high but remain within the capacity of the Basque Health Service. So far in Europe, no other population Colorectal Cancer screening programme has been evaluated by budget impact analysis.

Keywords: Colorectal Cancer, Mass screening, Cost-effectiveness analysis, Budget impact analysis

\section{Background}

The cost effectiveness of colorectal cancer (CRC) screening has been widely documented [1-4]. However, specific evaluations for different programmes are necessary because local CRC epidemiology (cancer incidence and adenoma prevalence) and the actual implementation of screening (type of test, attendance rate, and surveillance schedule) can cause variations in efficiency [4-6]. CRC in Basque country is characterized by unusual epidemiological features given that CRC incidence is similar to other European countries while adenoma prevalence is higher [7]. Therefore the need for independent evaluation is especially noteworthy. As with all public health interventions, cancer screening programmes must measure their value, i.e., the health outcomes achieved per euro spent for the whole population $[8,9]$.

The Basque CRC Screening Programme began in 2009 at the suggestion of the Cancer Advisory Council, which took into account the significant increase of both CRC incidence and mortality in the Basque Country from 1986 through 2008 [10-12]. Like most European programmes, it uses faecal immunochemical testing (FIT) to detect microscopic bleeding from adenomas or preclinical CRC [10, 13]. Individuals with positive test results are referred for a diagnostic colonoscopy and can then be assigned to a surveillance schedule [13]. As more cohorts are included in the programme, the number of colonoscopies grows, and programme feasibility relies on its capacity to respond to that demand $[3,5,14]$. The Basque CRC epidemiology of high adenomas prevalence may constitute a challenge because it may mean that the number of colonoscopies required in the CRC screening programme will be higher. Experts have underscored the need to tailor the implementation of CRC screening in populations within the context of organized programmes $[6,15]$.

During the first four years of implementation, the Basque programme performed 295,934 screening tests, and 17,146 diagnostic colonoscopies were carried out to confirm positive FIT results. Such marked resource consumption alone justifies conducting an economic assessment that takes into account the results in the middle and long term $[5,9]$. Besides the cost effectiveness, for a comprehensive economic evaluation, it is essential analysing the programme's affordability regarding the global budget impact [16]. This analysis addresses the expected changes in the expenditure of a healthcare system after the adoption of a new intervention [16]. As with other CRC screening programmes, sustainability analysis must also tackle the demand for colonoscopies to avoid future inability to meet the need $[2-6,15]$. To carry out the economic evaluation of cancer screening programmes, widespread use of decision models has been the rule generally, $[2-6]$ as well as in the Basque Country $[17,18]$.

Because the implementation of the Basque CRC programme has been complete since 2013, decisionmakers should now be informed as to whether the resources are appropriately allocated and the programme is sustainable given the high prevalence of adenomas. The object of our study was to economically evaluate the programme compared to no screening via cost-effectiveness and budget impact analyses with microsimulation models calibrated to the Basque epidemiological features of CRC incidence and adenoma prevalence $[11,19,20]$.

\section{Methods}

As the programme targeted the population between 50 and 69 years of age and used biennial FIT screening and complete colonoscopy to confirm positive results, its evaluation required follow-up of the target population at middle and long term. To estimate the economic results of the screening strategy implemented in the Basque Country, the Microsimulation Screening Analysis model for colorectal cancer (MISCAN-Colon) was applied. MISCAN-Colon is a stochastic microsimulation model for colorectal cancer (CRC) developed using Delphi programming language (Borland Software Corporation, Scotts Valley, California, United States). The aim of the model was to explain and predict CRC incidence and mortality trends, as well as, assessing the effect of primary prevention of CRC, screening for CRC, and surveillance after polypectomy in terms of both health and costs. The structure of the MISCAN-Colon model and the sources that inform the parameters of the model have been fully described in previous publications, [21-25] as well as in a standardised model profile of the Cancer Intervention and Screening Network (CISNET) [26]. A full description of the model was also included in the Model Appendix section of the Additional file 1. 
Individuals of a large population were simulated using MISCAN-Colon. They were created at birth and lifelong follow-up was applied. Natural history of CRC was included according to the adenoma-carcinoma sequence [27, 28]. The model assumes the possibility for more than one adenoma at the same time in each individual. Each adenoma can independently progress in size $(\leq 5 \mathrm{~mm}, 6-$ $9 \mathrm{~mm}, \geq 10 \mathrm{~mm}$ ) and develop into CRC. In addition, some will become malignant, transforming to stage I CRC; some cases of CRC may even progress to more advanced stages. At any stage, CRC may be diagnosed due to the development of symptoms. When CRC finally develops, the survival rate after diagnosis depends on the stage at which the cancer was detected. In addition, at any time during the individual's life, the process may be interrupted by his/ her death from other causes. With this model, the entire target population can be followed from birth to death to measure both the long-term costs and health outcomes related to the programme.

\section{Simulated population}

We reproduced the entire Basque population in 2008: 2,230,000 people, $51 \%$ women. The screening programme begun in 2009 was fully implemented by 2013. In order to reproduce the implementation strategy, the population was divided into different strata based on its age structure and the calendar year at which individuals were invited into the programme for the first time (or never invited in the event that they were 70 or older in 2009). In the model the continuation of the screening programme was set to 30 years (2009-2038). In this way the model enabled the evaluation of the screening as a public health intervention by estimating both lifetime costs and health benefits. Table 1 shows the data and sources used in the model. This study was approved by the Basque Country's Ethics Committee.

As the MISCAN-Colon model was developed within the CISNET group, [26] it was first calibrated to CRC epidemiology and demographics of the United States population. Therefore, to use it for the Basque population, the age-specific CRC incidence by location (colon and rectum) and stage distribution were calibrated to the incidence data from the Basque Cancer Registry for the years 20052008, prior to the implementation of the CRC screening programme. Simultaneously, the MISCAN-Colon model was calibrated to the adenoma detection rates calculated for the Basque population from the COLONPREV study [20]. Separate models were built for men and women due to epidemiological differences in the natural history of CRC.

\section{Screening scenario simulated}

Screening was simulated according to the design of the Basque colorectal cancer screening programme.
Table 1 Sources of parameters used in the adaptation of the MISCAN-Colon model to the Basque population and screening programme

\begin{tabular}{ll}
\hline Data & Source \\
\hline Demographics 2008 & $\begin{array}{l}\text { EUROSTAT - Basque Institute of } \\
\text { Statistics }\end{array}$ \\
$\begin{array}{l}\text { CRC incidence 2005-2008 } \\
\text { Adenomas prevalence Base case }\end{array}$ & $\begin{array}{l}\text { COLque Cancer registry } \\
\text { Adenomas prevalence Low }\end{array}$ \\
$\begin{array}{l}\text { Prevalence case } \\
\text { Costs screening }\end{array}$ & Basque CRC screening programme \\
Costs colonoscopy & Basque Health Service accounting \\
Sosts treatment & system \\
Utilities & Basque Health Service accounting \\
Invitations 2009-2013 & system \\
Participation 2009-2012 & [30] \\
Test features 2011-2012 & Basque CRC screening programme \\
\hline EUROSTAT Statistical Office of the European Union, CRC colorectal cancer
\end{tabular}

All individuals within the programme's age range biennially received an invitation letter that included a FIT. Delivering a sample to the assigned primary care health centre was necessary to have it analysed for microscopic bleeding. The cut-off was established at $20 \mu \mathrm{g} / \mathrm{g}$ faeces. Those participants with a positive test result were referred for colonoscopy. Furthermore, patients with at least one adenoma $>20 \mathrm{~mm}$ or five or more adenomas were recalled within a year for a surveillance colonoscopy and those with one adenoma $>10 \mathrm{~mm}$ or more than three adenomas or any adenomas with a villous component or high degree of dysplasia were invited for surveillance colonoscopy in three years, and all individuals with adenomas $<10 \mathrm{~mm}$ or 1 to 2 adenomas or tubular component or low degree of dysplasia were invited for regular FIT screening in 5 years. All recommendations were based on the European surveillance guidelines [13] adapted to the size-dependent classification in the model. A description of the surveillance protocol appears in the Additional file 2: Table S1. Participation rates both for FIT and colonoscopy were estimated for initial and successive invitations, depending on the individual's age as determined by available data from the Basque CRC Screening Programme in the period 2009-2012 (Table 1).

\section{Test characteristics}

Test characteristics were fitted to the positivity and detection rates of advanced neoplasia observed in the Basque programme between 2011 and 2012 (Additional file 2: Table S2). Advanced neoplasia included CRC and advanced adenomas, which were defined as adenomas $\geq 10 \mathrm{~mm}$ in size, with a $25 \%$ or greater villous component and/or high- 
grade dysplasia. The screening module was tested by reproducing invitations, participation and test results.

After the natural history of CRC without detection by screening was reproduced, the behaviour of CRC was reproduced according to the screening scenario, in which the impact of removing adenomas and anticipation of the CRC stage at diagnosis were considered. Those consequences were translated in quality-adjusted life years (QALY) gained and avoided costs in treatment.

\section{Costs and utilities}

We applied the perspective of the Basque Health Service, which is responsible for delivering screening to the entire Basque population between 50 and 69 years old. Unit costs were obtained in Euros (Sep 2012: 1 Euro $=1.25$ US dollars) from the accounting systems in the service. The resources assigned to each screened person were disaggregated by invitation (€6.06 including invitation letter, FIT and programme management resources), FIT analysis in participants (€0.99), primary care consultation in case of positive results $(€ 78.00)$ and colonoscopies (€461.30 with polypectomy and $€ 281.30$ without polypectomy). We also applied an average cost of $€ 5157.00$ for complications related to colonoscopy. To calculate the costs of CRC treatment, we retrospectively collected stage and resource use from a sample of 529 patients [29]. For stages I to III the initial and followup costs were measured. The calculation of cost for stage IV disease combined generalized linear models to relate the cost to the duration of follow-up on the basis of parametric survival analysis. Unit costs were obtained from the analytical accounting system of the Basque Health Service. The sample included 110 cases in stage I, 171 in stage II, 158 in stage III and 90 in stage IV. The initial total cost ranged from $€ 6968$ for stage I to $€ 12,765$ for stage II and $€ 13,075$ for stage III. The estimation of the annual cost for follow-up care included computed tomography, colonoscopy, tests and external consultations, and an amount of $€ 404$ was rendered. For those patients in stage IV specific initial treatment cost was not considered, however, the cost for each year of follow-up was $€ 24,255$. The details of the generalized linear model are reported in the Additional file 2: Table S3.

As specific preference values for the different stages of CRC were not available for the Basque or Spanish population, we incorporated utilities that were already in the MISCAN-Colon model (Additional file 2: Table S4) [29]. We assumed a utility loss (i.e., a loss of QALY) equivalent to two full days of life per colonoscopy $(0.0055$ QALY) and two weeks of life per complication (0.0384 QALY). We also assigned a utility loss to each life-year with CRC care (Additional file 2: Table S4) [30].

\section{Economic evaluation}

The economic evaluations included both the costeffectiveness analysis and the budget impact analysis (BIA) of the programme from the perspective of the Basque Health System. The evaluation period was defined as 2009 through December 31, 2038. The incremental cost-effectiveness ratio (ICER) incorporated the additional QALY gained in the denominator and the additional costs incurred by the programme in the numerator [9]. We applied a multi-cohort approach by including all the cohorts in the programme during 30 years of implementation from its beginning in 2009. After this period, from 2039 onwards, the programme did not include more cohorts, but maintained the intervention for all individuals already included in the screening programme. The entire population had lifetime follow-up in order to capture the longterm impact. Costs and QALYs were discounted by 3\%.

The microsimulation model was used simultaneously for BIA. The annual costs for CRC diagnosis and treatment in both the screened and unscreened populations from 2009 to 2038 were calculated in the model [16, 18]. Diagnostic resources included screening tests (FIT and diagnostic and surveillance colonoscopies) and clinical colonoscopies implemented in the reference hospital. It was not necessary to discount the costs because the BIA showed financial streams over time without aggregation [16].

\section{Sensitivity analysis}

To assess the impact of model assumptions in our results, three main sensitivity analyses were carried out: 1) A scenario including a lower prevalence of adenomas based on the literature [31-40] was run in addition to the base case model; 2) Because individuals with a false negative test result have a higher than average probability of another false negative test result at a successive screening, we also developed a new scenario in which dependency of FIT results in sequential screening rounds was assumed (Additional file 2: Table S2) [41]; 3) The impact of increasing the cost of screening was also estimated.

\section{Results \\ Goodness-of-fit}

Goodness-of-fit obtained in the MISCAN-Colon model adaptation for adenoma prevalence by age and gender, respectively, is shown in Fig. 1a and b and Model Appendix contain further validation details such as CRC incidence fitting. The model showed good concordance with the number of diagnostic colonoscopies observed in the Basque programme from 2009 to 2014 (Fig. 2a and b), validating the base scenario of high adenoma prevalence. Only in 2013 observed participation and positivity rates exceeded those simulated and the number of diagnostic colonoscopies carried out in the programme was also higher than forecasted. In 2014 


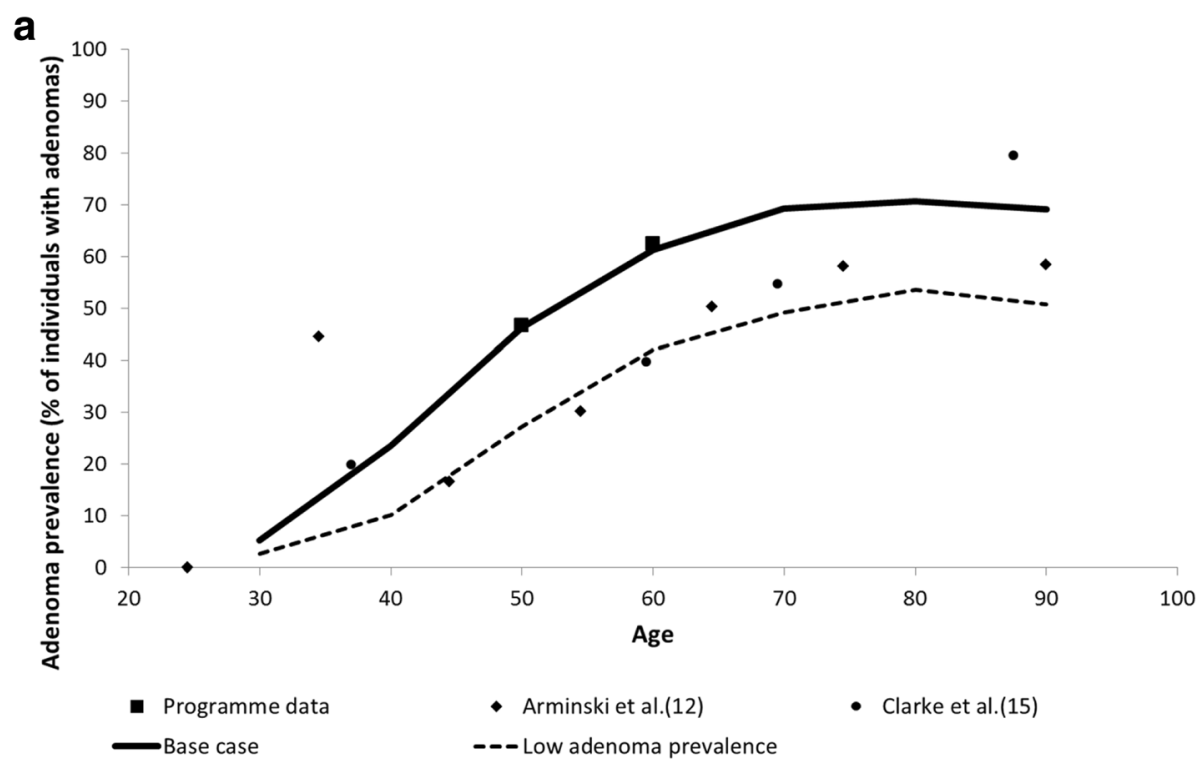

b

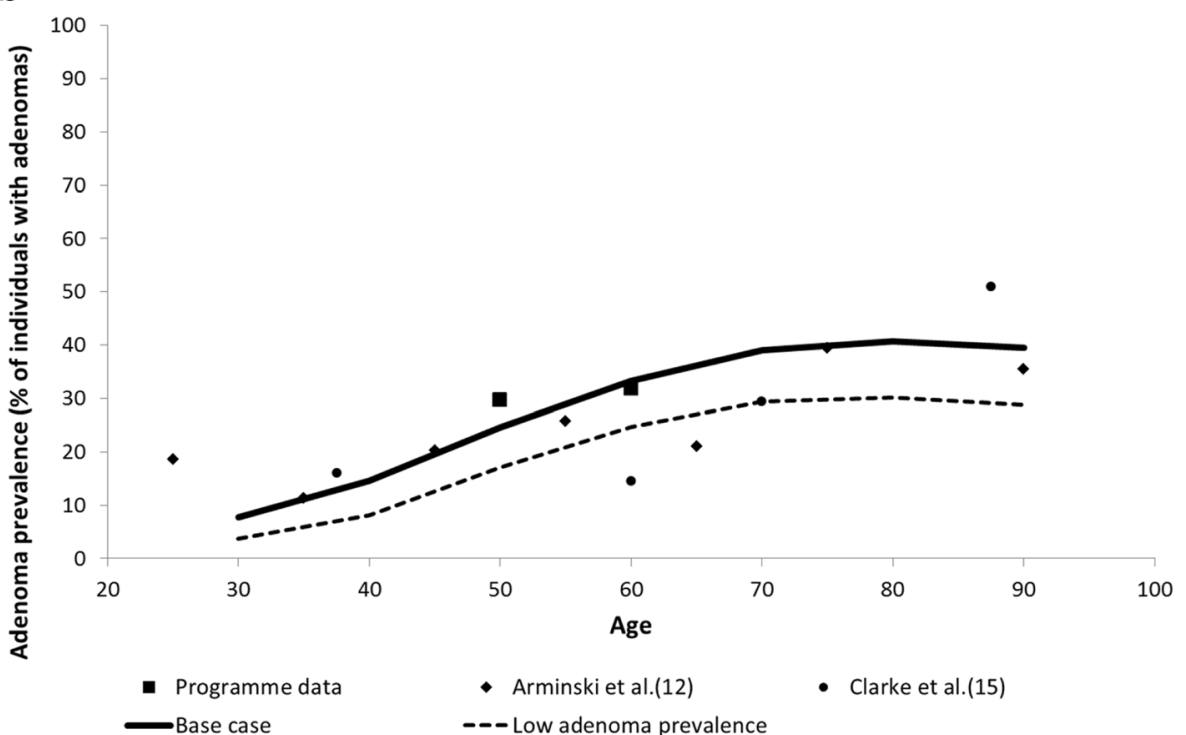

Fig. 1 Adenomas Prevalence Observed in COLONPREV study and other published studies Versus Simulated by MISCAN-Colon (\% of individuals with adenomas)*. a) Men; b) Women. ${ }^{*}$ Observed results are only shown for the two largest studies on which the model has been calibrated. MISCAN-Colon has additionally been calibrated to 8 other autopsy studies

the fit was better. Some other internal validation results, such as invitations and adherence to the programme and FIT characteristics in the period 2009-2014 were also used to validate model fitting and prediction behaviour (Additional file 2: Figure. S1 and Additional file 2: Figure S2). All these comparisons pointed to the good fit achieved in the adaptation of the MISCAN-Colon model to the Basque population and screening programme.

\section{Cost-effectiveness analysis}

Without screening, the target Basque population in 2008 was expected to live on average 41.1 years (Table 2).
After the implementation of the screening programme, that life expectancy increased by 29.3 days per person. This gain in terms of life-years involved an incremental effectiveness of 56,664.8 QALY (with 3\% discount) due to screening. The total cost for screening, diagnostic follow-up, surveillance and treatment, during the applied time horizon, was $€ 2057.2$ million (Table 2). However, because screening resulted in a substantial reduction of colorectal cancer incidence, there was a large reduction in the costs of treating CRC (256.3 $\mathrm{m} €$ ) and a net saving of €93.1 million (Table 2) compared to that in the unscreened population. Overall, these savings from treatment were larger 


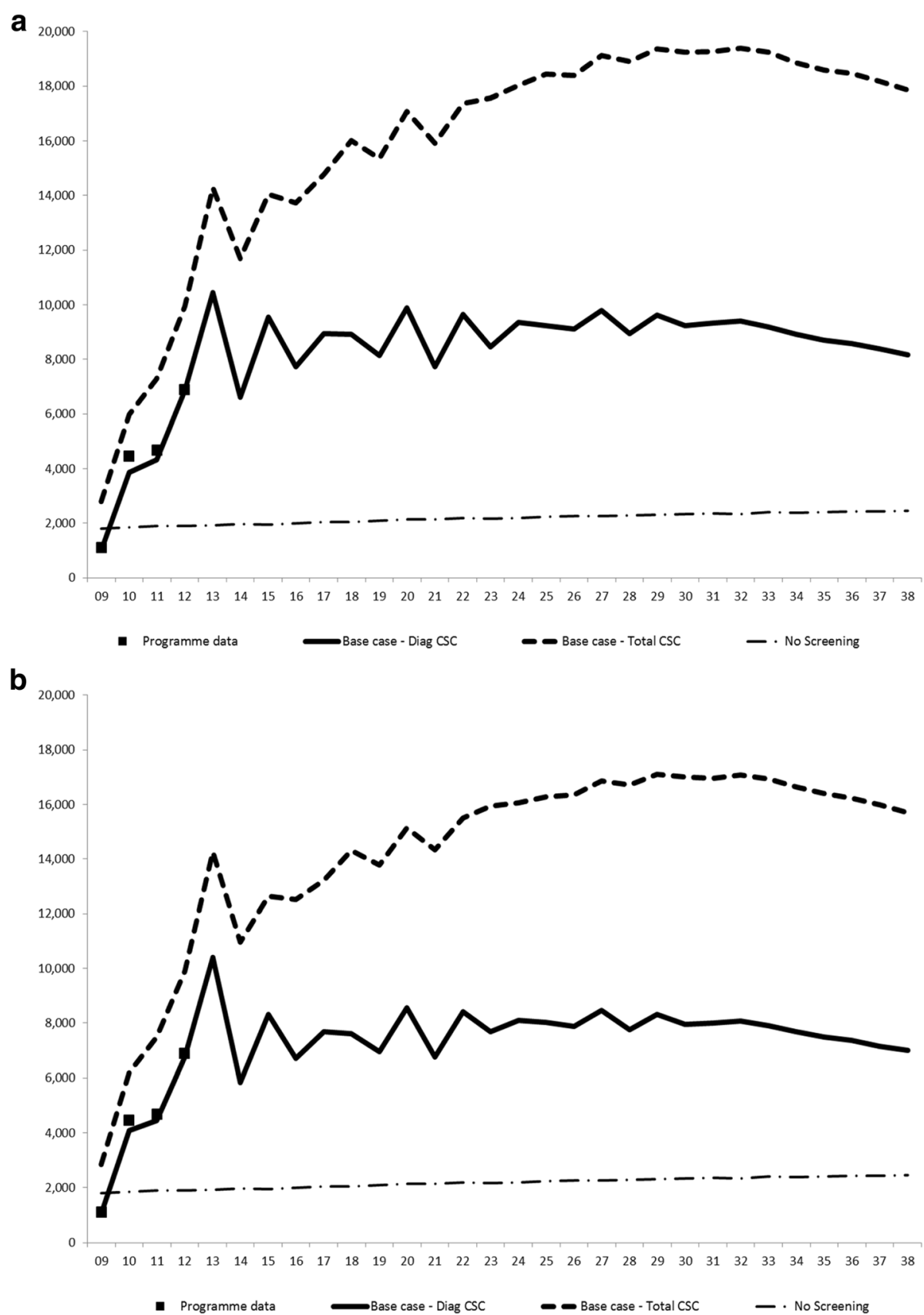

Fig. 2 Predicted number of diagnostic and total colonoscopies needed each year in base-case scenario. a) Independent successive screening tests; b) Correlated successive screening tests. Diag: diagnostic; CSC: colonoscopies

than the costs for screening, and thus, the Basque screening programme was dominant compared to no screening.

\section{Budget impact analysis}

Total and incremental costs related to screening, diagnosis and treatment of CRC in both scenarios (screened and unscreened) are displayed by year in Fig. 3. High screening costs due to the high number of positive test results for prevalent adenomas and cases of CRC were involved in the first four years after the introduction of screening until 2013, when $100 \%$ implementation was achieved. During the first five years of implementation, $€ 69.2$ million were necessary on average to annually fund the screening (Fig. 3 and Additional file 2: Table S5). The savings in the BIA appear in 2023, 10 years after the complete implementation of the programme. Even though the savings from screening were small at first, they increased as the impact of the programme became apparent. Figure 3 
Table 2 Sensitivity analysis for cost-effectiveness analysis of the implementation of colorectal cancer screening programme in the Basque population

\begin{tabular}{|c|c|c|c|c|c|c|c|}
\hline \multirow[b]{2}{*}{ Cost per invitation } & \multirow[b]{2}{*}{ Adenoma prevalence } & \multicolumn{2}{|c|}{ Screened population costs } & \multicolumn{2}{|c|}{ Incremental costs } & \multirow[t]{2}{*}{ QALYs gained } & \multirow[t]{2}{*}{ ICER } \\
\hline & & Treatment cost & Total costs & Treatment cost & $\overline{\text { Total costs }}$ & & \\
\hline \multirow[t]{8}{*}{$€ 6.06$ per invitation } & \multicolumn{7}{|l|}{ Base case } \\
\hline & Men & 1199.9 & 1317.0 & -179.1 & -81.7 & $37,132.5$ & Dominant \\
\hline & Women & 664.2 & 740.2 & -77.1 & -11.4 & $19,532.3$ & Dominant \\
\hline & Total & 1864.1 & 2057.2 & -256.3 & -93.1 & $56,664.8$ & Dominant \\
\hline & \multicolumn{7}{|l|}{ Prevalence Bibliography } \\
\hline & Men & 1227.5 & 1318.9 & -168.6 & -97.2 & $36,616.9$ & Dominant \\
\hline & Women & 661.0 & 726.9 & -77.6 & -21.8 & $20,438.5$ & Dominant \\
\hline & Total & 1888.5 & 2045.7 & -246.2 & -119.0 & $57,055.4$ & Dominant \\
\hline$€ 15.00$ per invitation & Base case - Total & 1864.1 & 2103.2 & -256.3 & -47.1 & $56,664.8$ & Dominant \\
\hline$€ 20.00$ per invitation & Base case - Total & 1864.1 & 2128.9 & -256.3 & -21.4 & $56,664.8$ & Dominant \\
\hline$€ 25.00$ per invitation & Base case - Total & 1864.1 & 2154.6 & -256.3 & 4.2 & $56,664.8$ & 74.1 \\
\hline$€ 30.00$ per invitation & Base case - Total & 1864.1 & 2180.3 & -256.3 & 30.0 & $56,664.8$ & 529.4 \\
\hline$€ 40.00$ per invitation & Base case - Total & 1864.1 & 2231.8 & -256.3 & 81.5 & $56,664.8$ & 1438.3 \\
\hline$€ 50.00$ per invitation & Base case - Total & 1864.1 & 2283.2 & -256.3 & 132.9 & $56,664.8$ & 2345.4 \\
\hline
\end{tabular}

ICER incremental cost effectiveness ratio

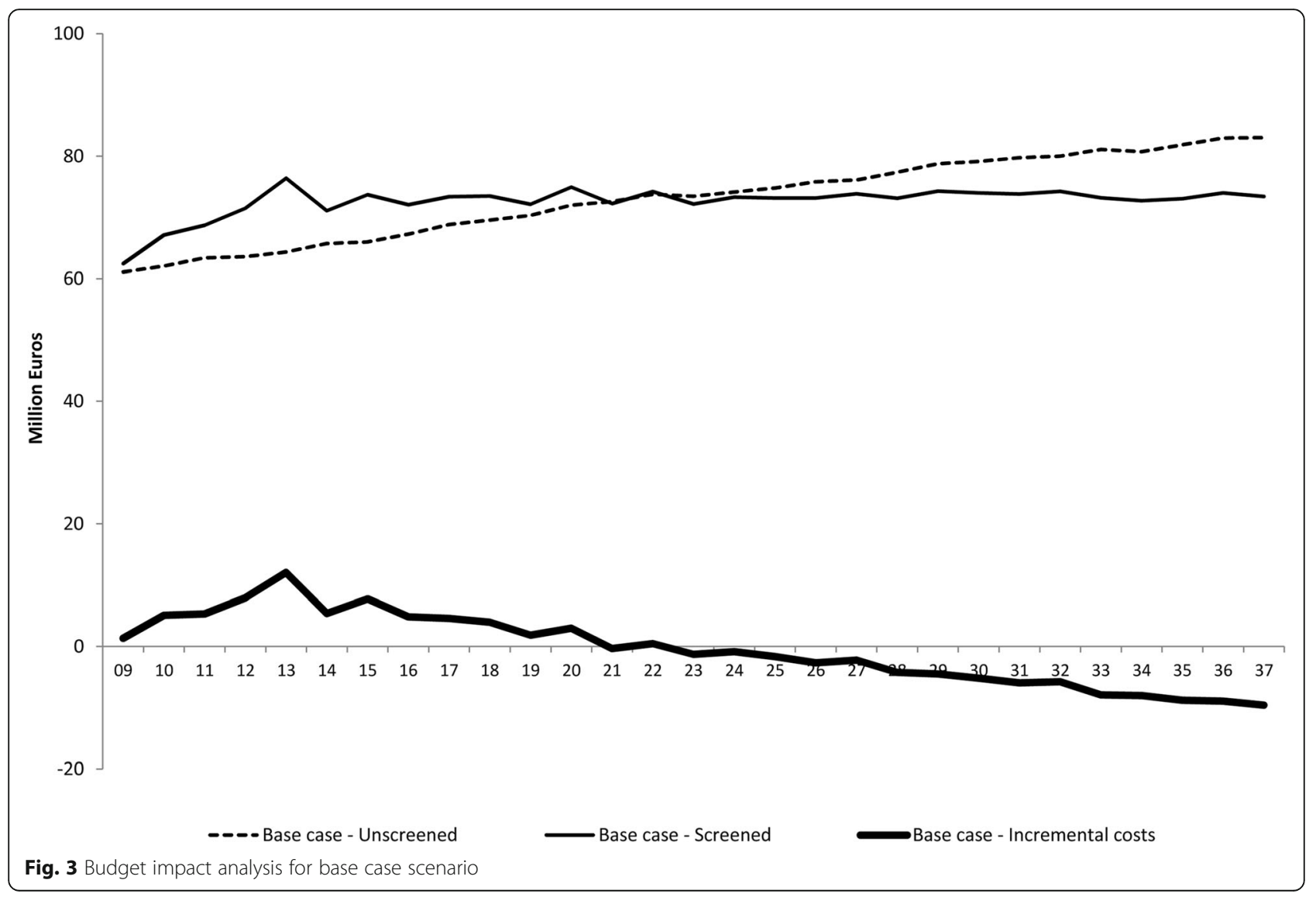


shows that the increase in the annual budget for the ageing unscreened population disappeared when screening was applied, and thus a stable annual budget of $€ 73.4$ million was achieved on average from year 2023 onwards.

In addition, the model predicted the number of colonoscopies during a 30-year period (Fig. 2), which reached a maximum in 2032 with 19,384. On average, the estimated annual number of colonoscopies (including diagnostic, surveillance and clinical colonoscopies) needed in the base case from 2029 through 2038 was 18,843 (52.5\% surveillance colonoscopies).

\section{Sensitivity analysis}

When a scenario with lower adenoma prevalence was set, the number of colonoscopies declined to 14,167 (Additional file 1: Figure. S3) and the net cost savings amounted to $€ 119$ million in the study period (Additional file 1: Figure. S4). Similarly, when the possibility of systematic false negative test results was included in the model, it was determined that fewer colonoscopies $(16,605)$ than estimated for the base case were necessary and involved a savings of €95.1 million compared to the no-screening scenario. Finally, when unit costs for screening invitations were increased, the model showed that the screening programme would remain cost-saving if the cost of an invitation remained $\leq 20 €$ per invitation ( $€ 21.4$ million saved) (Table 2).

\section{Discussion}

This cost-effectiveness analysis featured the Basque CRC screening programme as a dominant intervention because it produced net cost savings and health benefits [9]. Budget analysis also showed a consistent savings after 10 years of its complete implementation, highlighting the affordability of the programme [16]. Both approaches to economic evaluation reveal that only a long follow-up is able to capture the late economic benefit of the screening based on the decrease in the number of cases of CRC in early and advanced stages and the consequent reduction in need for treatment. So far in Europe, no other population-based CRC screening programme has been evaluated with a comprehensive approach including both cost-effectiveness and budget impact analysis to prove the programme's efficiency and affordability. Obviously, our results support the continuity of this preventive policy for CRC. Two literature reviews confirmed this finding, emphasising that colorectal cancer screening is cost effective or dominant compared with no screening $[42,43]$.

Public health programmes must be reappraised periodically to confirm that they have achieved planned results [44]. Modelling can also be useful in other countries to inform the population programme planning. Our sensitivity analysis showed the impact of the actual adenoma prevalence on the need of colonoscopies. A realistic estimation for the number of colonoscopies needed could be made based on the early report produced by the COLONPREV study [20].

Different strategies for CRC screening are supported by the evidence. As the Basque programme is based on FIT, our assessment cannot avoid comparison with an alternative approach based on colonoscopy as the first test, which is the norm in the United States. To make that comparison, however, the number of colonoscopies required for effective screening must be considered. Any evaluation must assess if a health system has the capacity to absorb such increased demand for screening colonoscopies. Typically, when the demand exceeds the capacity to deliver, the implementation of the programme is obstructed. Moreover, the required number of colonoscopies is directly related to the prevalence of adenomas in the specific population $[14,19]$. In our study, this indicator was especially noteworthy because the adenoma prevalence in the Basque sample of the COLONPREV study yielded a higher number than that used in the MISCAN-Colon model [20]. The consequence of this finding could jeopardize the sustainability of the programme. The higher prevalence showed that 4200 more colonoscopies annually were necessary on average than were needed in the scenario based on a low prevalence. Both numbers were lower in the scenario in which dependency of FIT results in sequential screening rounds was assumed, that is, taking into account that individuals with a false negative test result have a higher than average probability of another false negative test result at a successive screening [41]. These predicted figures highlight the sustainability of the programme in operational terms, because the number of necessary diagnostic colonoscopies stabilized at approximately 8000 , which was the number already being delivered. However, the maximum capacity of the Basque Health System to carry out screening colonoscopies has been reached. Thus, any other proposal for CRC screening that led to more colonoscopies would not be feasible with the currently available resources. As colonoscopies delivery become usually a bottleneck in the process of implementing CRC screening.

To explain the long-term cost savings, we need to underline that although the screening programme and the derived colonoscopies meant a significant expense, more than $90 \%$ of the total expenditure originated with treatment costs. To reach this conclusion, future results had to be predicted. So, although the number of required colonoscopies rose with increasing prevalence of adenomas, the impact on the total cost was limited [20,31]. The total costs in the unscreened scenario grew steadily during the analysed years because the number of CRC cases in the Basque population rose with the aging of the baby boomers. The main component of those costs was the treatment costs that were proportional to the incidence. 
It is noteworthy that screening impact meant stabilization in total costs because the raw incidence was maintained and, therefore, the CRC age-adjusted rates decreased.

Decision-making on the basis of models is not without limitations. Although we used a model of high quality (MISCAN-Colon), which was adjusted to the epidemiology of the Basque population and the characteristics of the programme, model calibration was meant to force some parameters such as the classification of adenomas. The programme information system categories are riskbased, whereas the MISCAN-Colon model sorts them by size. The problem was resolved by reclassifying the adenomas found in the programme according to size. We understand that this adjustment did not involve any threat to the validity of the results, given the exhaustive process of calibration and validation. In addition, only costs related to the screening programme and CRC treatment were considered in the analysis; thus, we did not take into account the of cost of care of unrelated diseases that could appear due to increasing survival time. Including these costs could increase the final ICER and reduced the efficiency of the screening. Finally, the model did not include a probabilistic sensitivity analysis that is the norm in pharmacoeconomics, because of the difficulty of the computational burden in public health studies in which required dynamic models can include millions of individuals. However, the thorough calibration algorithm in MISCAN-Colon and the comprehensive internal and external validation warrant its robustness and, therefore, the reliability of the results.

Some of the differing results achieved in cost-effectiveness studies have been attributed to the dissimilarities in structure and parameters of the models applied to follow the entire life of the target population. The natural history of CRC as represented by the MISCAN-Colon model is shared by other CISNET partners, and its consistency has been fully proven $[45,46]$. Moreover, the calibration of the MISCAN-Colon model to fit the epidemiology of CRC and adenoma prevalence in the Basque country was achieved by internal and external validation. As Patel et al. pointed out, preclinical time, screening unit costs in each setting or screening adherence, none of which is the same in all studies, can explain heterogeneous results [43]. Good intermediate indicators of programme performance, such as participation rate $(64.3 \%$ in $2009-$ 2011) and waiting time for colonoscopy (30 days), also show that the programme is on track and help to explain the final economic saving [10, 47]. Significantly, that conclusion was also valid when the unit cost of screening was doubled.

It is also important to put into context the relative costs of the screening programme, as they represented between $6 \%$ and $8 \%$ of the total cost, when we aggregated the costs of the whole follow-up. Furthermore, that percentage range will probably decrease, as treatment costs tend to grow as a consequence of the introduction of new drugs much more expensive than those currently on the market [48]. As oncology drugs become less cost effective because of rising prices over time [48], the role of preventive policies is enhanced. Thus, our results support the idea that reinforcement of screening seems a plausible future option. Consideration of inequalities in access to health care also sustains investments in screening, rather than treatment. Although differences by social class have been found in the screening programme, it is easier to provide disadvantaged groups with better access to screening services than to provide the entire population with the latest oncological drugs [49].

The BIA approach to economic evaluation is used less often than the cost-effectiveness design, but it is a complementary and useful tool to show financial streams over time. Usually the trade-offs between incurred and saved costs are shown with a short time horizon, but the BIA easily allows the application of a long follow-up to capture the full economic and health benefit of the screening programme. This is consistent with the natural history of CRC and has been underscored in the literature [5]. An extended period of time is required for the impact of polypectomies on avoided deaths and cancer treatments to manifest, and thus, the first years of the programme can be misleading because the change in natural history of CRC has not reached a steady state in terms of the population [47].

\section{Conclusions}

We would like to emphasise that this evaluation reaffirms for decision-makers that the allocated resources for maintaining the programme are a worthwhile investment. This economic evaluation showed a screening intervention with a major health gain that also produced net savings when a long follow-up was used to capture the late economic benefit. Our results support the continuity of the Basque Colorectal Cancer Screnning Programme. Due to the actual adenoma prevalence reported in the COLONPREV study a realistic estimation of the future need of colonoscopies was necessary. The number of colonoscopies required was high but remain within the capacity of the Basque Health Service. So far in Europe, no other population Colorectal Cancer screening programme has been evaluated by budget impact analysis. Budget impact analysis highlighted the affordability of the programme showing consistent savings after 10 years of complete implementation.

\section{Additional files}

Additional file 1: Model Appendix. Detailed description of the MISCAN-Colon model and the adaptation procedure. (PDF $2242 \mathrm{~kb}$ )

Additional file 2: Table S1. European guidelines for surveillance schedule after colonoscopy adapted to the size-dependent classification 
used in the model. Table S2. Test characteristics by sex fitted to the positivity and detection rates of advanced neoplasia observed in the Basque programme between 2011 and 2012. Table S3. Generalized liner model applied to estimate annual follow-up cost in patients with metastatic colorectal cancer. Table S4. Disutility values used in the model for colonoscopy, its complications and four cancer states depending on cancer detection stage. Table S5. Budget impact analysis of the colorectal cancer programme in million euros. Figure S1. Number of invited and participant population: Observed data in the Basque Screening Programme Versus Simulated by MISCAN-Colon. Figure S2. Number of detected adenomas and cases of cancer: Observed data in the Basque Screening Programme Versus Simulated by MISCAN-Colon. Figure S3. Predicted number of diagnostic and total colonoscopies needed each year in base-case and low prevalence scenarios. Figure S4. Budget impact analysis for base case and lower adenoma prevalence scenarios. (PDF $1299 \mathrm{~kb}$ )

\section{Abbreviations}

BIA: Budget impact analysis; CISNET: Cancer Intervention and Screening Network; CRC: Colorectal Cancer; FIT: Faecal Immunochemical Testing; ICER: Incremental cost-effectiveness ratio; MISCAN: Microsimulation Screening Analysis; QALY: Quality adjusted life years

\section{Acknowledgements}

We would like to acknowledge the editorial assistance provided by Sally Ebeling.

\section{Funding}

This study was funded by the Basque Government Health Department (file number 2013111156). The funding sources had no influence on study design, data collection, monitoring, analysis and interpretation of results. Neither had they in the decision to submit the manuscript for publication.

\section{Availability of data and materials}

The anonymized administrative datasets used and analysed during the current study are available from the corresponding author on reasonable request. Due to the Spanish Royal Decree 1720/2007, 21st December, regulation of the Organic Law 15/1999 for Personal Data Protection the datasets are not publicly available.

\section{Authors' contributions}

Study concept and design: AA, II, JM, IP, ILV; Acquisition of data: II, IP, EAA, ILV; Model adaptation: AA, HdK, MvdM, ILV; Model validation: AA, II, JM, HdK, MvdM, IP, ILV; Cost analysis: JM, MSG, JMML, Ol; Statistical analysis and interpretation of the results: AA, II, JM, MSG, IP, EAA, OI, ILV; Drafting of manuscript: AA, JM, IP, ILV; All authors have read and approved the final version of the manuscript.

\section{Ethics approval and consent to participate}

This study was approved by the Basque Country's Ethics Committee (Reference number PI2014171) according to the principles expressed in the Declaration of Helsinki on 4th November 2014. Researchers affiliated to the Colorectal Cancer Screening Programme in the Basque Country obtained the correspondent administrative permission to work with anonymized institutional data in this project. Informed consent was not applicable for the use of anonymized population data required for the MISCAN model, complying with the Spanish Royal Decree 1720/2007, 21st December, regulation of the Organic Law 15/1999 for Personal Data Protection.

\section{Competing interests}

The authors declare that they have no competing interests.

\section{Publisher's Note}

Springer Nature remains neutral with regard to jurisdictional claims in published maps and institutional affiliations.

\section{Author details}

${ }^{1}$ Gipuzkoa Primary Care - Integrated Health Care Organizations Research Unit, Alto Deba Integrated Health Care Organisation, Avda Navarra 16, 20500
Arrasate-Mondragón, Gipuzkoa, Spain. ${ }^{2}$ Health Services Research on Chronic Patients Network (REDISSEC), Arrasate - Mondragón, Gipuzkoa, Spain. ${ }^{3}$ Biodonostia Health Research Institute, Donostia - San Sebastian, Gipuzkoa, Spain. ${ }^{4}$ Basque Country Colorectal Cancer Screening Programme, Basque Health Service, Bilbao, Bizkaia, Spain. ${ }^{5}$ Clinical Management Unit, Alto Deba Integrated Health Care Organisation, Arrasate - Mondragón, Gipuzkoa, Spain. ${ }^{6}$ Department of Public Health, Erasmus MC, University Medical Center, Rotterdam, The Netherlands. ${ }^{7}$ Accounting Department, Alto Deba Integrated Health Care Organisation, Arrasate - Mondragón, Gipuzkoa, Spain. ${ }^{8}$ BioCruces Health Research Institute, Barakaldo, Bizkaia, Spain.

Received: 9 June 2017 Accepted: 11 April 2018

Published online: 25 April 2018

\section{References}

1. US Preventive Services Task Force. Screening for colorectal cancer: US preventive services task force recommendation statement. Ann Intern Med. 2008;149(9):627-37.

2. Wilschut JA, Hol L, Dekker E, Jansen JB, Van Leerdam ME, Lansdorp-Vogelaar I, Kuipers EJ, Habbema JD, Van Ballegooijen M. Cost-effectiveness analysis of a quantitative immunochemical test for colorectal cancer screening. Gastroenterology. 2011;141(5):1648-55.

3. Tappenden P, Chilcott J, Eggington S, Patnick J, Sakai H, Karnon J. Option appraisal of population-based colorectal cancer screening programmes in England. Gut. 2007:56(5):677-84.

4. Pickhardt PJ, Hassan C, Laghi A, Zullo A, Kim DH, Morini S. Costeffectiveness of colorectal cancer screening with computed tomography colonography - the impact of not reporting diminutive lesions. Cancer. 2007:109:2213-21.

5. van Hees F, Zauber AG, van Veldhuizen $H$, Heijnen ML, Penning $C$, de Koning $\mathrm{HJ}$, van Ballegooijen M, Lansdorp-Vogelaar I. The value of models in informing resource allocation in colorectal cancer screening: the case of the Netherlands. Gut. 2015:64:1985-97.

6. van Ballegooijen M, Rutter CM, Knudsen AB, Zauber AG, Savarino JE, Lansdorp-Vogelaar I, Boer R, Feuer EJ, Habbema JD, Kuntz KM. Clarifying differences in natural history between models of screening: the case of colorectal cancer. Med Decis Mak. 2011:31:540-9.

7. Center MM, Jemal A, Smith RA, Ward E. Worldwide variation in colorectal cancer. CA Cancer J Clin. 2009;59(6):366-78.

8. Porter ME. What is value in health care? N Engl J Med. 2010;363:2477-81.

9. Russell LB, Gold MR, Siegel JE, Daniels N, Weinstein MC. The role of costeffectiveness analysis in health and medicine. JAMA. 1996;276(14):1172-7.

10. Portillo I, Idígoras I, Ojembarrena E, Arana-Arri E, Zubero MB, Pijoán Jl, López Urrutia A Marqués ML. Principales resultados del programa de cribado de cáncer colorrectal en el País Vasco. Gac Sanit. 2013;27:358-61.

11. Departamento de Sanidad y Consumo del Gobierno Vasco. El cáncer en el País Vasco. Incidencia, mortalidad, supervivencia y evolución temporal. Bilbao: Servicio Central de Publicaciones del Gobierno Vasco; 2010.

12. López-Abente G, Ardanaz E, Torrella-Ramos A, et al. Changes in colorectal cancer incidence and mortality trends in Spain. Ann Oncol. 2010; 21(Suppl 3):):576-82.

13. Segnan N, Patnick J, von Karsa L, Editores. European Commission. European guidelines for quality assurance in colorectal cancer screening and diagnosis. Brussels: European Commission; 2011.

14. Wilschut JA, Habbema JD, van Leerdam ME, Hol L, Lansdorp-Vogelaar I, Kuipers EJ, van Ballegooijen M. Fecal occult blood testing when colonoscopy capacity is limited. J Natl Cancer Inst. 2011;103(23):1741-51.

15. Brenner $H$, Stock C, Hoffmeister M. Colorectal cancer screening: the time to act is now. BMC Med. 2015:13:262.

16. Sullivan SD, Mauskopf JA, Augustovski F, Jaime Caro J, Lee KM, Minchin M, Orlewska E, Penna P, Rodriguez Barrios JM, Shau WY. Budget impact analysis-principles of good practice: report of the ISPOR 2012 budget impact analysis good practice II task force. Value Health. 2014;17(1):5-14.

17. Arrospide A, Rue M, van Ravesteyn NT, Comas M, Larrañaga N, Sarriugarte G, Mar J. Evaluation of health benefits and harms of the breast cancer screening programme in the Basque Country using discrete event simulation. BMC Cancer. 2015;15:671.

18. Arrospide A, Rue M, van Ravesteyn NT, Comas M, Soto-Gordoa M Sarriugarte G, Mar J. Economic evaluation of the breast cancer screening programme in the Basque Country: retrospective cost-effectiveness and budget impact analysis. BMC Cancer 2016;16(1):344. 
19. Corley DA, Jensen CD, Marks AR, Zhao WK, Lee JK, Doubeni CA, Zauber AG, de Boer J, Fireman BH, Schottinger JE, Quinn VP, Ghai NR, Levin TR, Quesenberry CP. Adenoma detection rate and risk of colorectal cancer and death. N Engl J Med. 2014;370(14):1298-306.

20. Quintero E, Castells A, Bujanda L, Cubiella J, Salas D, Lanas Á, et al. COLONPREV study investigators. Colonoscopy versus fecal immunochemica testing in colorectal-cancer screening. N Engl J Med. 2012;366(8):697-706.

21. Loeve F, Boer R, van Oortmarssen GJ, et al. The MISCAN-COLON simulation model for the evaluation of colorectal cancer screening. Comput Biomed Res. 1999:32:13e33.

22. Loeve F, Boer R, van Ballegooijen M, et al. Final report MISCANeCOLON microsimulation model for colorectal Cancer: report to the National Cancer Institute project NO. NO1-CN55186. Rotterdam: Department of Public health, Erasmus University; 1998.

23. Lansdorp-Vogelaar I, van Ballegooijen M, Boer R, et al. A novel hypothesis on the sensitivity of the fecal occult blood test: results of a joint analysis of 3 randomized controlled trials. Cancer. 2009;115:2410e19.

24. Loeve F, Boer R, Zauber AG, et al. National polyp study data: evidence for regression of adenomas. Int J Cancer. 2004;111:633e9.

25. Vogelaar I, van Ballegooijen M, Schrag D, et al. How much can current interventions reduce colorectal cancer mortality in the U.S.? Mortality projections for scenarios of risk-factor modification, screening, and treatment. Cancer. 2006;107:1624e33.

26. Vogelaar I, van Ballegooijen M, Zauber AG. Model Profiler of the MISCANColon Microsimulation Model For Colorectal Cancer. Department of Public health, Erasmus Medical Center. https://cisnet.flexkb.net/mp/pub/cisnet_ colorectal_sloankettering_profile.pdf. Accessed 23 Feb 2016.

27. Muto T, Bussey HJ, Morson BC. The evolution of cancer of the colon and rectum. Cancer. 1975;36:2251e70.

28. Rutter $C M$, Knudsen AB, Marsh TL, Doria-Rose VP, Johnson E, Pabiniak C, Kuntz KM, van Ballegooijen M, Zauber AG, Lansdorp-Vogelaar I. Validation of models used to inform colorectal Cancer screening guidelines: accuracy and implications. Med Decis Mak. 2016;36(5):604-14.

29. Mar J, Errasti J, Soto-Gordoa M, Mar-Barrutia G, Martinez-Llorente JM Domínguez S, García-Albás JJ, Arrospide A. The cost of colorectal cancer according to the TNM stage. Cirugía Española. 2017;95(2):89-96.

30. Ness RM, Holmes AM, Klein R, Dittus R. Utility valuations for outcome states of colorectal cancer. Am J Gastroenterol. 1999;94(6):1650-7.

31. Arminski TC, MClean DW. Incidence and distribution of adenomatous polyps of the colon and rectum based on 1,000 autopsy examinations. Dis Colon rectum. 1964;7:249-61.

32. Blatt L. Polyps of the Colon and Rectum: incidence and distribution. Dis Colon rectum. 1961:4:277-82.

33. Bombi JA. Polyps of the colon in Barcelona, Spain. An autopsy study. Cancer. 1988:61(7):1472-6.

34. Chapman I. Adenomatous polypi of large intestine: incidence and distribution. Ann Surg. 1963:157:223-6.

35. Clark JC, Collan Y, Eide TJ, Estève J, Ewen S, Gibbs NM, Jensen OM, Koskela E, MacLennan R, Simpson JG, et al. Prevalence of polyps in an autopsy series from areas with varying incidence of large-bowel cancer. Int J Cancer. 1985;36(2):179-86.

36. Jass JR, Young PJ, Robinson EM. Predictors of presence, multiplicity, size and dysplasia of colorectal adenomas. A necropsy study in New Zealand. Gut. 1992:33(11):1508-14

37. Johannsen LG, Momsen O, Jacobsen NO. Polyps of the large intestine in Aarhus, Denmark. An autopsy study. Scand J Gastroenterol. 1989;24(7):799-806.

38. Rickert RR, Auerbach O, Garfinkel L, Hammond EC, Frasca JM. Adenomatous lesions of the large bowel: an autopsy survey. Cancer. 1979;43(5):1847-57.

39. Vatn $M H$, Stalsberg $H$. The prevalence of polyps of the large intestine in Oslo: an autopsy study. Cancer. 1982;49(4):819-25.

40. Williams AR, Balasooriya BA, Day DW. Polyps and cancer of the large bowel: a necropsy study in Liverpool. Gut. 1982;23(10):835-42.

41. van der Meulen MP, Lansdorp-Vogelaar I, van Heijningen EM, Kuipers EJ, van Ballegooijen M. Nonbleeding adenomas: evidence of systematic falsenegative fecal immunochemical test results and their implications for screening effectiveness-a modeling study. Cancer. 2016;122:1680-8.

42. Lansdorp-Vogelaar I, Knudsen AB, Brenner H. Cost-effectiveness of colorectal cancer screening. Epidemiol Rev. 2011;33:88-100.

43. Patel SS, Kilgore ML. Cost effectiveness of colorectal Cancer screening strategies. Cancer Control. 2015;22(2):248-58.

44. Tappenden P, Chilcott J, Brennan A, Squires H, Glynne-Jones R, Tappenden J. Using whole disease modeling to inform resource allocation decisions: economic evaluation of a clinical guideline for colorectal Cancer using a single model. Value Health. 2013;16:542-53.

45. Knudsen AB, Lansdorp-Vogelaar I, Rutter CM, et al. Cost-effectiveness of computed tomographic colonography screening for colorectal cancer in the Medicare population. J Natl Cancer Inst. 2010;102(16):1238-52.

46. Kuntz KM, Lansdorp-Vogelaar I, Rutter CM, Knudsen AB, van Ballegooijen M, Savarino JE, Feuer EJ, Zauber AG. A systematic comparison of microsimulation models of colorectal cancer: the role of assumptions about adenoma progression. Med Decis Mak. 2011;31(4):530-9.

47. Rabeneck L, Lansdorp-Vogelaar I. Assessment of a cancer screening program. Best Pract Res Clin Gastroenterol. 2015;29(6):979-85.

48. Cressman S, Browman GP, Hoch JS, Kovacic L, Peacock SJ. A time-trend economic analysis of Cancer drug trials. Oncologist. 2015;20:729-36.

49. Hurtado JL, Bacigalupe A, Calvo M, Esnaola S, Mendizabal N, Portillo I, Idigoras I, Millán E, Arana-Arri E. Social inequalities in a population based colorectal cancer screening programme in the Basque Country. BMC Public Health. 2015;15:1021.

\section{Ready to submit your research? Choose BMC and benefit from:}

- fast, convenient online submission

- thorough peer review by experienced researchers in your field

- rapid publication on acceptance

- support for research data, including large and complex data types

- gold Open Access which fosters wider collaboration and increased citations

- maximum visibility for your research: over $100 \mathrm{M}$ website views per year

At BMC, research is always in progress.

Learn more biomedcentral.com/submissions 